\title{
KEANEKARAGAMAN TUMBUHAN OBAT DI DESA SIMPANG KUBU KECAMATAN KAMPAR KABUPATEN KAMPAR PROVINSI RIAU
}

\author{
Wirdati Irma dan Awari Susanti \\ Program Studi Biologi FMIPA dan Kesehatan Universitas Muhammadiyah Riau
}

\begin{abstract}
ABSTRAK
Tumbuhan Indonesia sangat kaya dengan berbagai spesies dan keanekaragaman, salah satunya adalah keanekaragaman tumbuhan obat. Penelitian keanekaragaman tumbuhan obat di Desa Simpang Kubu Kec. Kampar Kab. Kampar Provinsi Riau ini bertujuan untuk mengetahui jenis keanekaragaman tumbuhan obat dan mengetahui potensi dari masing-masing spesies yang di peroleh dari Desa Simpang Kubu Kec. Kampar Kab. Kampar Provinsi Riau. Adapun metode yang digunakan adalah wawancara dan survei. Untuk survei di lapangan mengambil 4 lokasi penelitian, yakni pekarangan rumah masyarakat, daerah aliran sungai yang dekat dengan pemukiman masyarakat, jalan utama dan kebun masyarakat, sementara teknik wawancara dalam penentuan sampel menggunakan porposive sampling pada masyarakat yang mengerti dan paham tentang tumbuhan obat seperti, tetua adat, dukun, bidan, dan masing-masing koresponden pada setiap dusun diambil 1 (satu) orang perwakilan. Hasil yang diperoleh dari wawancara dan survei di lapangan diperoleh 38 spesies tumbuhan obat termasuk dalam 24 famili dan 33 genus di mana famili yang paling banyak adalah Zinggiberaceae, Euphorbiaceae, Lamiaceae dan Melastomataceae. Adapun potensi dari 38 jenis tumbuhan obat yang ditemukan pada penelitian ini yakni dapat di gunakan untuk mengobati penyakit dengan jumlah penyakit sebanyak 71 jenis penyakit.
\end{abstract}

Kata kunci: keanekaragaman, tumbuhan obat, potensi, penyakit, porposive sampling

\section{PENDAHULUAN}

Flora Indonesia sangat kaya dengan berbagai spesies dan keanekaragamannya. Sebagai gambaran kekayaan dan keanekaragaman flora Indonesia, Steenis (2005) memperkirakan bahwa jumlah spesies tanaman berbunga saja antara $25.000-30.000$ jenis. Sedangkan koleksi herbarium yang berada di Pusat Penelitian dan Pengembangan Hutan di Bogor mempunyai lebih dari 4.000 spesies pohon dalam 668 genus yang termasuk dalam 111 famili. Sedangkan dari herbarium yang terdapat sebagai koleksi khusus tanaman-tanaman yang mempunyai nilai ekonomis, khususnya tanaman obat yang disebut sebagai koleksi Heyne, mempunyai 3302 spesies dalam 1468 genus dan termasuk dalam 199 famili.

Menurut Zein (2005) bangsa Indonesia kaya akan sumber bahan obat alam dan tradisional yang telah digunakan oleh sebagian besar masyarakat Indonesia secara turun temurun. Keuntungan obat tradisional yang digunakan langsung oleh masyarakat adalah kemudahan untuk memperolehnya dan bahan bakunya dapat ditanam di pekarangan sendiri, murah dan dapat diramu sendiri di rumah. Hampir setiap orang Indonesia pernah menggunakan tumbuhan obat untuk mengobati penyakit atau kelainan yang terdapat pada tubuhnya karena manfaat tumbuhan obat ini diakui dapat menyembuhkan atau meredakan penyakit yang diderita. Menurut Cahyadi (2009) masyarakat Indonesia telah lama mengenal serta menggunakan obat-obatan alami atau yang dikenal dengan nama obat tradisional. Obat tradisional lebih mudah diterima oleh masyarakat karena obat ini lebih murah dan mudah didapat.

Penggunaan tumbuhan obat secara tradisional semakin disukai karena pada umumnya tidak menimbulkan efek samping, seperti halnya obatobatan dari bahan kimia. Penggunaan obat itu sendiri sangat beraneka ragam, ada yang digunakan untuk menyembuhkan penyakit dan untuk mempercantik diri (kosmetik) (Wakidi, 2003). Penggunaan tumbuh-tumbuhan sebagai obat tradisional semakin disukai dan diminati 
karena memiliki keunggulan pada bahan dasarnya yang bersifat alami sehingga efek sampingnya dapat ditekan seminimal mungkin (Utami, 2008).

Tumbuhan obat memiliki sifat dan karakteristik masing-masing, tumbuhan obat bisa berupa tumbuhan sejenis semak, rumput, jamur, umbi-umbian, bahkan tanaman besar yang berkayu. Bagian tumbuhan yang digunakan bisa berupa batang, daun, biji, kulit kayu dan akar (Nurmalina, 2012).

Tumbuhan sebagai bahan baku utama obatobatan tradisional diketahui dan dipercaya oleh masyarakat luas memiliki khasiat obat yang mampu mengatasi berbagai macam penyakit pada diri manusia. Diprediksi hal ini dapat terjadi karena tumbuhan mengandung beberapa senyawa kimia alami yang terbukti memiliki aktivitas biologi baik secara in-vitro maupun in-vivo. Diketahui terdapat sekitar 10.000 jenis tumbuhan dari 300.000 tumbuhan tinggi di muka bumi telah dimanfaatkan untuk tujuan pengobatan. Diperkirakan terdapat 122 jenis obat yang pembuatannya berasal dari 94 jenis tumbuhan yang berbeda, dan dari jumlah ini $72 \%$ diperoleh dari data pemanfaatan etnobotani (Fabricant \& Farnsworth dalam Kardono \& Kartawinata,
2007). Di kawasan Asia Tenggara diprediksi terdapat 425 jenis tumbuhan yang dapat dimanfaatkan sebagai bahan obat (Valkenburg \& Bunyapraphatsara, 2002).

Pada dekade belakangan ini, penelitian tentang jenis-jenis tumbuhan yang berpotensi obat telah banyak dilakukan begitu juga penelitian tentang pengetahuan dan pemanfaatan tumbuhan obat oleh masyarakatlokal, di antaranya oleh Susiarti et al., (2001) di kawasan Tesso Nillo. Hasil penelitiannya menemukan 87 jenis dari 48 famili yang digunakan sebagai obat oleh penduduk setempat. Jenis-jenis tumbuhan tersebut antara lain termasuk dalam famili Zingiberaceae dan Poaceae. Berdasarkan hasil penelitian yang dilakukan oleh Bendraliza (2001) di Kecamatan Rokan IV koto Kabupaten Rokan Hulu ditemukan 125 jenis tumbuhan obat dari 66 famili, yang didominasi oleh famili Gramineae, Euphorbiaceae, Zingiberaceae, dan Solanaceae. Selain itu penelitian yang di daerah lain seperti penelitian yang sudah dilakukan Setyowati (2007) tercatat 69 jenis tumbuhan yang dimanfaatkan sebagai obat tradisional.

Beberapa contoh tumbuhan obat dan khasiatnya dapat di lihat seperti pada tabel berikut ini.

Tabel 1.

Beberapa Contoh Tumbuhan Obat Dan Senyawa Kimia yang Terkandung di Dalam Tumbuhan Obat.

\begin{tabular}{|l|l|l|l|}
\hline \multicolumn{1}{|c|}{ Nama Tumbuhan Obat } & \multicolumn{1}{|c|}{ Famili } & \multicolumn{1}{c|}{ Khasiat } & \multicolumn{1}{c|}{ Sumber } \\
\hline $\begin{array}{l}\text { Kumis Kucing (Orthosiphon } \\
\text { spicatus) }\end{array}$ & Lamiaceae & $\begin{array}{l}\text { Anti radang, menurunkan } \\
\text { panas, peluruh kentut, dan } \\
\text { menghancurkan batu } \\
\text { saluran kencing. }\end{array}$ & Dalimarta (2000) \\
\hline $\begin{array}{l}\text { Sambiloto (Andrographis } \\
\text { paniculata) }\end{array}$ & Acanthaceae & $\begin{array}{l}\text { Influenza, sakit kepala, } \\
\text { penghilang nyeri, } \\
\text { menyembuhkan panas } \\
\text { dalam, penawar racun. }\end{array}$ & \\
\hline $\begin{array}{l}\text { Mangkokan (Nothapanax } \\
\text { scutallarium) }\end{array}$ & Araliaceae & $\begin{array}{l}\text { Bau badan, luka bakar, } \\
\text { radang payudarah, } \\
\text { memperlancar ASI. }\end{array}$ & \\
\hline $\begin{array}{l}\text { Gadung (Dioscorea hipsida } \\
\text { Dennust) }\end{array}$ & Dioscoreaceae & $\begin{array}{l}\text { Keputihan, kencing } \\
\text { manis, kusta, nyeri haid } \\
\text { dan rematik. }\end{array}$ & Widyaningrum(2011) \\
\hline $\begin{array}{l}\text { Kunyit (Curcuma longa Linnn) } \\
\text { Zingiberaceae }\end{array}$ & $\begin{array}{l}\text { Diabetes, amandel, tifus, } \\
\text { usus buntu, memperlancar } \\
\text { ASI dan disentri. }\end{array}$ & \\
\hline
\end{tabular}




\begin{tabular}{|c|l|l|l|}
\hline Nama Tumbuhan Obat & \multicolumn{1}{|c|}{ Famili } & \multicolumn{1}{c|}{ Khasiat } & \multicolumn{1}{|l|}{ Sumber } \\
\hline Pacing (Costus megalobrachtea) & Zingiberaceae & $\begin{array}{l}\text { Obat sakit mata, penyubur } \\
\text { menghilangkan gatal-gtal. }\end{array}$ & \\
\hline
\end{tabular}

Desa Simpang Kubu merupakan salah satu desa yang terdapat di Kabupaten Kampar. Masyarakat Desa Simpang Kubu sampai saat ini masih menggunakan tumbuhan sebagai alternatif pengobatan penyakit, terutama untuk mengobati penyakit ringan seperti demam, batuk, sakit perut dan sakit kepala. Pengobatan ini biasanya dilakukan oleh dukun kampung setempat.Adapun data keanekaragaman jenis tumbuhan yang berpotensi sebagai obat yang terdapat di Desa Simpang Kubu belum ada, untuk itu penelitian tentang identifikasi tumbuhan obat perlu dilakukan di Desa Simpang Kubu.

Dari kenyataan yang telah diungkapkan di atas maka tujuan dari pada penelitian ini adalah untuk mengetahui keanekaragaman jenis tumbuhan obat serta potensi penyakit apa saja yang dapat diobati dari tumbuhan obat yang terdapat di Desa Simpang Kubu Kec. Kampar Kab. Kampar Provinsi Riau tersebut.

\section{METODOLOGI PENELITIAN}

Pelaksanaan penelitian dilakukan di Desa Simpang Kubu, Kecamatan Kampar, Kabupaten Kampar Provinsi Riau. Sampel diambil di tiga dusun yaitu dusun Panglima Khotib, Metro Lestari, dan Padang Beringin. Sampel diidentifikasi di Laboratorium Biologi FMIPA Universitas Muhammadiyah Riau.

Bahan yang digunakan dalam penelitian ini adalah alkohol $70 \%$. Alat yang digunakan adalah kamera, gunting tanaman, kantong plastik, kertas label, alat-alat tulis dan perlengkapan herbarium yang meliputi kertas koran, tali rafia dan kardus. Metode yang digunakan dalam penelitian ini adalah metode survei. Data yang digunakan adalah data primer dan sekunder, dimana data primer diperoleh dengan cara menanyakan langsung (wawancara) kepada penduduk, tokoh masyarakat Desa Simpang Kubu yang secara langsung menggunakan dan mengetahui tumbuhtumbuhan tersebut sebagai obat. Data diperoleh dengan cara survei untuk mengumpulkan spesimen tumbuh-tumbuhan obat yang ada kemudian tumbuhan tersebut dibuat herbarium dan, secara sekunder data diidentifikasi dengan menggunakan buku acuan menurut Utami (2008), Hariana (2004) Widyaningrum (2011), Dalimarta (2000), dan Steenis (2005).

\section{A. Teknik Pengumpulan Data}

Teknik pengumpulan data dilakukan dengan dua cara yaitu melalui wawancara dan survei lapangan.

1. Wawancara

Pengumpulan data berupa panduan wawancara yang disusun dalam bentuk pertanyaan yang meliputi:

a) Nama lokal.

b) Bagian tumbuhan yang digunakan (akar, batang, daun, buah, dan biji).

c) Khasiat (macam-macam penyakit yang bisa disembuhkan).

d) Cara pembuatan (misalnya direbus, ditumbuk, digiling, diremas dan dibakar).

e) Cara penggunaan (misalnya dimakan, diminum, dan ditempel).

f) Habitat tumbuhan obat tradisional ditentukan dengan metode Purposive Sampling dengan lokasi dipekarangan, ladang, pinggir jalan,dan pinggir sungai.

Responden dipilih 15 orang sebagai perwakilan dilakukan secara Purposive Sampling yaitu anggota masyarakat yang mengetahui tentang pengobatan tradisional seperti tetua adat, dukun, bidan, dan orang-orang yang tahu tentang sistem atau cara pengobatan tradisional dan setiap dusun diambil 1 (satu) orang perwakilan dari masing-masing dusun.

2. Survei Lapangan

Survei lapangan dilakukan untuk mengumpulkan jenis-jenis tanaman obat. Survei ini difokuskan pada 4 lokasi:

a) Pekarangan masyarakat Desa Simpang Kubu Dusun Panglima Khotib, Metro Lestari dan 
Padang Beringin yang menanam berbagai macam jenis tumbuhan obat.

b) Daerah aliran sungai yang dekat dari pemukiman masyarakat Dusun Panglima Khotib dan Metro Lestari karena dusun ini dilewati oleh sungai.

c) Pinggir-pinggir jalan utama Desa Simpang Kubu Dusun Panglima Khotib, Metro Lestari dan Padang Beringin.

d) Perkebunan masyarakat yang masih ditumbuhi tanaman obat.

Tanaman yang diperoleh diidentifikasi di Laboratorium Biologi Universitas Muhammadiyah Riau.

\section{B. Pembuatan Herbarium}

Herbarium dilakukan pada tumbuhan yang tidak dikenal jenisnya. Tumbuhan obat tersebut diambil semua bagiannya baik akar, batang, daun, bunga. Kemudian dicatat keterangan mengenai tumbuhan obat tersebut secara umum misalnya habitat, morfologi, warna, bentuk bunga atau buah. Kemudian dilakukan proses pembuatan herbarium yang diawali dengan membersihkan semua bagian organ tumbuhan tersebut sehingga tidak ada lagi tanah yang menempel, baru diberi alkohol $70 \%$ secara merata di seluruh bagian tumbuhan tersebut. Setelah itu tanaman tersebut diletakkan di antara kertas koran yang diapit dengan kardus kemudian diikat dengan menggunakan pengapit yang kuat seperti sasak bambu dan diikat dengan tali. Kemudian tumbuhan tersebut dikeringkan dengan menggunakan sinar matahari. Setiap hari posisi tumbuhan obat diubah untuk menghindari pemanasan pada satu sisi saja dan ini dilakukan selama 1 minggu/7 hari. Setelah tumbuhan obat benar-benar kering, baru ditempelkan pada kertas herbarium yang berukuran $29-31 \mathrm{~cm}$ x 40-42 cm (Fauziah dan Suryawati, 2001).

\section{Identifikasi Tumbuhan Obat}

Tumbuhan obat yang telah diperoleh, dikumpulkan kemudian diidentifikasi jenisnya, identifikasi tumbuhan obat dilakukan dengan menanyakan identitas tumbuhan obat, mencocokkan tumbuhan obat dengan yang ada dalam buku-buku atau atlas tumbuhan obat Indonesia Jilid II (Dalimarta, 2000) dan menggunakan kunci identifikasi yang mengacu pada buku Flora (Steenis, 2005).

\section{Analisis Data}

Data yang diperoleh ditabulasikan dan dianalisis secara deskriptif berdasarkan:

1. Taksonomi yang meliputi, nama lokal, nama Indonesia, nama latin, dan famili tumbuhan obat.

2. Tempat tumbuhan obat diambil.

3. Bagian tumbuhan yang dimanfaatkan sebagai obat, meliputi akar, batang, daun, bunga dan buah.

4. Khasiat atau kegunaan.

5. Cara pengolahan (dihaluskan, diremas, dibakar dan direbus).

6. Cara penggunaan (dimakan, diminum, ditempelkan, dan digosokkan).

\section{HASIL DAN PEMBAHASAN}

Dari hasil pengambilan tumbuhan obat di Desa Simpang Kubu Kec. Kampar Kab. Kampar Provinsi Riau telah dapat diidentifikasi sebanyak 38 spesies tumbuhan, dimana tumbuhan tersebut dapat dilihat pada tabel berikut:

Tabel 2. Jenis-jenis Tumbuhan Obat.

\begin{tabular}{|l|l|l|l|l|l|}
\hline No & \multicolumn{1}{|c|}{ Famili } & \multicolumn{1}{|c|}{ Nama Spesies } & Nama Daerah & \multicolumn{1}{|c|}{ Lokasi } & \multicolumn{1}{|c|}{ Kasiat } \\
\hline 1 & Acantaceae & $\begin{array}{l}\text { Andrographis } \\
\text { paniculata }\end{array}$ & Sambiloto & ST 1,2 & Influenza, diare,kangker \\
\hline 2 & Amaryllidaceae & $\begin{array}{l}\text { Hymenocallis } \\
\text { litthoralis }\end{array}$ & Bakung & ST 1,3,4 & Anti septik \\
\hline 3 & Apiaceae & Centella asiatica & Kaki kuda & ST 1,3 & $\begin{array}{l}\text { Mag, Tipus, Busung Lapar, } \\
\text { Bau badan }\end{array}$ \\
\hline 4 & Araliacea & $\begin{array}{l}\text { Nothopanax } \\
\text { scutellarium }\end{array}$ & Mangkokan & ST 1 & $\begin{array}{l}\text { Radang Payudara, Pelancar } \\
\text { ASI, Luka, Bau badan }\end{array}$ \\
\hline 5 & Asphodelaceae & Aloe vera & Lidah Buaya & ST 1 & $\begin{array}{l}\text { Luka bakar, Cacing, } \\
\text { Mata,anti kangker,bisul, },\end{array}$ \\
\hline
\end{tabular}




\begin{tabular}{|c|c|c|c|c|c|}
\hline No & Famili & Nama Spesies & Nama Daerah & Lokasi & Kasiat \\
\hline & & & & & mengurangi kadar gula \\
\hline 6 & Asteraceae & Blumea balsamifera & Sembung & ST 1,2 & $\begin{array}{l}\text { Influenza, nyeri haid,sakit } \\
\text { tulang }\end{array}$ \\
\hline 7 & Caricaceae & Carica papaya & Pepaya & ST 1,2 & $\begin{array}{l}\text { Diare,malaria,nyeri haid, } \\
\text { batu ginjal, rematik, } \\
\text { hipertensi }\end{array}$ \\
\hline 8 & Campanulaceae & Isotoma longiflora & Bunga Bintang & ST 1,4 & $\begin{array}{l}\text { Asma,mata,luka,gigi, } \\
\text { kangker }\end{array}$ \\
\hline 9 & Crassulaceae & Kalanchoe pinnata & Cocor Bebek & ST 1 & $\begin{array}{l}\text { Bisul,amandel,deman, sakit } \\
\text { kepala, radang payudara, }\end{array}$ \\
\hline \multirow[t]{5}{*}{10} & Euphorbiaceae & Phyllantus niruri & Meniran & ST $1,3,4$ & Sakit kuning,lever, malaria \\
\hline & & & & & Deman, ayan, batuk,luka \\
\hline & & Jatropha multifida & Jarak Tintir & ST 3,4 & $\begin{array}{l}\text { Memar, luka, mencegah } \\
\text { kerusakan gigi }\end{array}$ \\
\hline & & J. curcas & Jarak Pagar & ST 1 & $\begin{array}{l}\text { Luka, terkilir, bengkak, } \\
\text { rematik, gatal-gatal }\end{array}$ \\
\hline & & Souropus androginus & Katu & ST 1,4 & $\begin{array}{l}\text { Deman, pelancar ASI, } \\
\text { bisul, demam }\end{array}$ \\
\hline \multirow[t]{3}{*}{11} & Lam & $\begin{array}{l}\text { Coleus } \\
\text { atropurpureus }\end{array}$ & Iler & ST $1,2,3$ & $\begin{array}{l}\text { Demam, diare, diabetes, } \\
\text { ambien, bisul }\end{array}$ \\
\hline & & Ortosiphon spicatus & Kumis Kucing & ST 1,4 & $\begin{array}{l}\text { Kencing batu, infeksi } \\
\text { ginjal, infeksi kantong } \\
\text { kemih }\end{array}$ \\
\hline & & Pogostemon cablin & Nilam & ST 1,4 & $\begin{array}{l}\text { Jamur, kulit peceh-pecah, } \\
\text { anti septik }\end{array}$ \\
\hline 12 & Lythraceae & Lowsonia inermis & Inai Kayu & ST 1 & $\begin{array}{l}\text { Kalestrol, penurun gula } \\
\text { darah, }\end{array}$ \\
\hline 13 & Malvaceae & $\begin{array}{ll}\text { Hibiscus rosa- } \\
\text { sinensis }\end{array}$ & $\begin{array}{l}\text { Kembang } \\
\text { Sepatu }\end{array}$ & ST 1,4 & Demam, batuk, sariawan \\
\hline \multirow[t]{2}{*}{14} & Melastomataceae & Melostoma candidum & Sikeduduk & ST 3,4 & $\begin{array}{l}\text { Keputihan, penarahan } \\
\text { rahim, diare, hepatitis, } \\
\text { mimisan, memperlancar } \\
\text { ASI }\end{array}$ \\
\hline & & Diascorea hispida & Gadung & ST 4 & $\begin{array}{l}\text { Kencing manis, rematik, } \\
\text { nyeri haid }\end{array}$ \\
\hline \multirow[t]{2}{*}{15} & Myrtaceae & $\begin{array}{l}\text { Rhadomyrtus } \\
\text { tamentosa }\end{array}$ & Kalimunting & ST 3,4 & Wasir, nyeri haid, hipatitis \\
\hline & & Psidium guajava & Jambu Biji & ST $1,3,4$ & $\begin{array}{l}\text { Diabetes, sakit perut, } \\
\text { masuk angin }\end{array}$ \\
\hline 16 & Oleaceae & Jasminum sambac & Melati & ST 1 & Sakit kepala, sesak nafas \\
\hline \multirow[t]{2}{*}{17} & Oxalidaceae & Averrhoa bilimbi & $\begin{array}{l}\text { Belimbing } \\
\text { wuluh }\end{array}$ & ST 1,4 & Hipertensi, diabets, batuk, \\
\hline & & & & & Rematik \\
\hline 18 & Piperaceae & Piper betle & Sirih & ST 1,4 & $\begin{array}{l}\text { Mimisan, bau mulut, mata, } \\
\text { batuk, sariawan, keputihan, } \\
\text { gigi, diare }\end{array}$ \\
\hline 19 & Poaceae & A, ndropogon nardus & Serai wangi & ST 1,4 & $\begin{array}{l}\text { Batuk, kumur, habis } \\
\text { melahirkan, nafsu makan }\end{array}$ \\
\hline 20 & Rubiaceae & Morinda citrifolia & Mengkudu & ST $1,3,4$ & $\begin{array}{l}\text { Sakit kuning, demam, } \\
\text { batuk, sakit perut, influenza }\end{array}$ \\
\hline \multirow[t]{2}{*}{21} & Rutaceae & Citrus aurantifolia & Jeruk Nipis & ST 1,4 & $\begin{array}{l}\text { Sesak nafas, amandel, } \\
\text { batuk, malaria, influenza, } \\
\text { haid }\end{array}$ \\
\hline & & C. medica & Jeruk Pepaya & ST 1,4 & $\begin{array}{l}\text { Mag, sakit tenggorokan, } \\
\text { bau badan }\end{array}$ \\
\hline 22 & Selonaceae & Solanum torvum & Rimbang & ST 1,4 & $\begin{array}{l}\text { Hipertensi, mata, nyeri } \\
\text { haid, kencing manis, }\end{array}$ \\
\hline
\end{tabular}




\begin{tabular}{|l|l|l|l|l|l|}
\hline No & \multicolumn{1}{|c|}{ Famili } & \multicolumn{1}{|c|}{ Nama Spesies } & Nama Daerah & \multicolumn{1}{c|}{ Lokasi } & \multicolumn{1}{|c|}{ Kasiat } \\
\hline & & & & & jerawat \\
\hline 23 & Verbenaceae & Cylea barbata & Cincau & ST 2,4 & $\begin{array}{l}\text { Hipertensi, demam, } \\
\text { sariawan }\end{array}$ \\
\hline 24 & Zingiberaceae & Curcuma domestika & Kunyit & ST 1,4 & $\begin{array}{l}\text { Diare, luka dalam, masuk } \\
\text { angin, diabetes militus, } \\
\text { tupus, usus buntu, disentri, } \\
\text { memperlancar ASI }\end{array}$ \\
\hline & & C. xanthorriza & Temulawak & ST 1,4 & $\begin{array}{l}\text { Pinggang, nyeri haid, nafsu } \\
\text { makan, ginjal, asma, mag }\end{array}$ \\
\hline & Renguas galanga & Lengkuas & ST 4 & $\begin{array}{l}\text { Rematik, limfa, brongkitis, } \\
\text { panu }\end{array}$ \\
\hline & & Zingiber officinale & Jahe & ST 1,4 & $\begin{array}{l}\text { Mules, kepala, nafsu } \\
\text { makan, batuk, luka }\end{array}$ \\
\hline & Z. Purpureum & Bangle & ST 1,4 & Sakit kuning, masuk angin \\
\hline & $\begin{array}{l}\text { Costus } \\
\text { megalobrachtea }\end{array}$ & Pacing & ST 4 & $\begin{array}{l}\text { Memar, luka, menyuburkan } \\
\text { rambut, mata, gatal-gatal }\end{array}$ \\
\hline & Kaempferia galanga & Kencur & ST 1,4 & $\begin{array}{l}\text { Radang lambung, radang } \\
\text { anak telinga, darah kotor, } \\
\text { haid, diare }\end{array}$ \\
\hline
\end{tabular}

Keterangan:

ST 1 : Pekarangan.; ST 2: Aliran Sungai; ST 3: Jalan Utama; ST 4 : Kebun

Dari Pengambilan data primer di lapangan diperoleh 38 jenis tumbuhan obat di Desa Simpang Kubu yang diklasifikasikan dalam 24 famili yang digunakan oleh masyarakat sebagai bahan pengobatan tradisional. Tumbuhan obat yang diperoleh banyak terdapat di pekarangan dan kebun. Spesies tumbuhan obat yang banyak dijumpai dipekarangan biasanya sengaja di tanam oleh masyarakat. penanaman spesies tumbuhan obat tersebut oleh masyarakat ada yang sudah mereka ketahui manfaatnya sebagai tanaman obat, di samping juga masih banyak dari spesies tersebut yang masyarakat juga tidak mengetahui manfaatnya.

Dari seluruh jenis keanekaragaman tumbuhan obat yang dijumpai, famili yang dominan dijumpai adalah Zingiberaceae dengan spesies ; Curcuma domestika, Curcuma xanthorriza, Renguas galanga, Zingiber officinale, Zingiber purpureum, Costus megalobrachtea, Kaempferia galanga, sementara yang sering diguna kan olehmasyarakat untuk pengobatan adalah famili Zinggiberaceae, Euphorbiaceae, Lamiaceae dan Melastomataceae yang terdiri dari 16 spesies tumbuhan obat.

Potensi dari spesies tumbuhan obat yang dapat digunakan untuk pengobatan penyakit dari 38 spesies yang dijumpai pada Desa Simpang
Kubu Kec. Kampar Kab. Kampar Provinsi Riau tidak hanya dapat mengatasi satu jenis penyakit, namun bisa dua, tiga dan bahkan ada yang sampai 8 jenis penyakit yang bisa diatasi hanya dengan menggunakan satu spesies tumbuhan obat saja misalnya pada spesies Curcuma dimestica dengan nama daerah kunyit yang termasuk ke dalam famili Zingiberaceae. Kunyit ini dapat mengobati penyakit diare, luka dalam, masuk angin, diabetes militus, tipus, usus buntu disentri dan dapat pula memperlancar ASI bagi ibu menyusui. Demikian juga dengan sirih dengan nama latin piper batle dari famili Piperaceae juga dapat mengobati berbagai macam penyakit seperti mimisan, mata, batuk, sariawan, keputihan, gigi, diare dan bau mulut. Dari seluruh spesies yang dijumpai di lokasi peneliatian dapat mengobati sebanyak 71 jenis penyakit, yang serig digunakan adalah untuk mengobati penyakit luka, mengatasi nyeri haid, batuk, menurunkan panas badan akibat demam, mengobati diare, rematik, penyakit mata, influenza, pelancar ASI, bisul, hipertensi dan diabetes.

\section{KESIMPULAN}

Berdasarkan dari hasil penelitian tentang keanekaragaman tumbuhan obat di Desa 
Simpang Kubu Kec. Kampar Kab. Kampar Provinsi Riau dapat di simpulkan:

1. Jumlah jenis tumbuhan obat yang dimanfaatkan oleh masyarakat Desa Simpang Kubu Kecamatan Kampar Kabupaten Kampar yaitu 38 jenis yang terbagi dalam 24 famili.Jenis tumbuhan yang banyak digunakan sebagai obat adalah famili Zinggiberaceae, Euphorbiaceae, Lamiaceae dan Melastomataceae dan Tumbuhan obat yang diperoleh banyak terdapat di pekarangan dan kebun.

2. Potensi dari 38 spesies tumbuhan obat yang di jumpai pada Desa simpang Kubu Kec. Kampar Kab. Kampar Provinsi Riau dapat mengobati 71 jenis penyakit.

\section{DAFTAR PUSTAKA}

Bendraliza, 2001. Inventarisasi Jenis-jenis tumbuhan obat pada pengobatan tradisional di Kecamatan Rokan IV koto Kabupaten Rokan Hulu. Riau [Skripsi]. FKIP UNRI. Jurusan Biologi.

Cahyadi, R. 2009. Uji Toksisitas Akut Ekstrak Etanol Buah Pare, (Momordika charantia L.) terhadap larva Artemia salina Leach dengan metode brine shrimp lethality test (BST). Kedokteran UNDIP Semarang.

Dalimarta, S. 2000. Atlas Tumbuhan Obat Indonesia, Jilid 2. Jakarta: Trubus Agriwidiya.

Fauziah, Y dan Suryawati, E. 2001. Buku Penuntun Pembuatan Herbarium. Kerjasama Lembaga Pusat Penelitian PT. Caltek Pasific Indonesia.
Hariana, A. 2004. Tumbuhan Obat dan Khasiatnya. Jakarta: Penebar Swadaya.

Nurmalina, R. 2012. Herbal Legendaris Untuk Kesehatan Anda. Jakarta. PT. Elex Media Komputindo.

Setyowati, F., M, 2007. Keanekaragaman Pemanfaatan Tumbuhan Masyarakat di Sekitar Taman Nasional Gunung Leuser. Jurnal Botani,Puslit. Biologi-LIPI No. 22, Bogor.

Steenis, VCGGJ 2005. Flora Untuk Sekolah di Indonesia. Jakarta. PT. Pradnya Paramita.

Susiarti, S., Y purwanto, EB waluyo, 2001. Keanekaragaman Tumbuhan Obat di Kawasan Tesso Nillo, Riau. Bogor. Pusat penelitian Biologi. Lipi.

Utami, P, 2008. Buku Pintar Tanaman Obat. Jakarta: AgroMedia.

Wakidi, 2003. Pemasyarakatan TanamanObat Keluarga "TOGA" Untuk Mendukung Penggunaan Sendiri. Kedokteran USU, Medan. Jurnal 2003 Digitized by USU Digital library.

Widyaningrum, H. 2011. Kitab Tanaman Obat Nusantara. Jakarta: PT. Buku Seru.

Zein, U, 2005. Pemanfaatan Tumbuhan Obat Dalam Upaya Pemeliharaan Kesehatan. (Divisi Penyakit Tropik dan Infeksi Bagian Ilmu Penyakit Dalam) Fakultas Kedokteran, USU, Medan. Jurnal e-USU Repository 2005 Universitas Sumatra Utara. 